Article

\title{
Deriving the Dietary Approaches to Stop Hypertension (DASH) Score in Women from Seven Pregnancy Cohorts from the European ALPHABET Consortium
}

\author{
Adrien M. Aubert ${ }^{1}$, Anne Forhan ${ }^{1}$, Blandine de Lauzon-Guillain $\left.{ }^{1}{ }^{(}\right)$, Ling-Wei Chen $\left.{ }^{2}{ }^{(}\right)$, \\ Kinga Polanska ${ }^{3}\left(\mathbb{D}\right.$, Wojciech Hanke ${ }^{3} \mathbb{D}$, Agnieszka Jankowska $^{3}$, Sara M. Mensink-Bout ${ }^{4,5}$, \\ Liesbeth Duijts ${ }^{4,5,6}$, Matthew Suderman ${ }^{7}$ (D), Caroline L. Relton ${ }^{7}$, Sarah R. Crozier ${ }^{8}$ (D), \\ Nicholas C. Harvey ${ }^{8,9}$, Cyrus Cooper ${ }^{8,9,10} \mathbb{D}^{\text {, Fionnuala M. McAuliffe }}{ }^{11}$, Cecily C. Kelleher ${ }^{2}$, \\ Catherine M. Phillips ${ }^{2} \mathbb{D}$, Barbara Heude ${ }^{1, *,+} \mathbb{D}$ and Jonathan Y. Bernard ${ }^{1,12,+}(\mathbb{D}$ \\ 1 Centre for Research in Epidemiology and StatisticS (CRESS), Université de Paris, Inserm, Inra, F-75004 Paris, \\ France; adrien.aubert@inserm.fr (A.M.A.); anne.forhan@inserm.fr (A.F.); \\ blandine.delauzon@inserm.fr (B.d.L.-G.); jonathan.bernard@inserm.fr (J.Y.B.) \\ 2 HRB Centre for Health and Diet Research, School of Public Health, Physiotherapy, and Sports Science, \\ University College Dublin, Belfield, Dublin 4, Ireland; ling-wei.chen@ucd.ie (L.-W.C.); \\ cecily.kelleher@ucd.ie (C.C.K.); catherine.phillips@ucd.ie (C.M.P.) \\ 3 Department of Environmental Epidemiology, Nofer Institute of Occupational Medicine, 91-348 Lodz, Poland; \\ kinga.polanska@imp.lodz.pl (K.P.); wojciech.hanke@imp.lodz.pl (W.H.); \\ agnieszka.jankowska@imp.lodz.pl (A.J.) \\ 4 The Generation R Study Group, Erasmus MC, University Medical Center Rotterdam, 3000 CA Rotterdam, \\ The Netherlands; s.mensink-bout@erasmusmc.nl (S.M.M.-B.); 1.duijts@erasmusmc.nl (L.D.) \\ 5 Department of Pediatrics, Division of Respiratory Medicine and Allergology, Erasmus MC, University \\ Medical Center Rotterdam, 3000 CB Rotterdam, The Netherlands \\ 6 Department of Pediatrics, division of Neonatology, Erasmus MC, University Medical Center Rotterdam, \\ 3000 CB Rotterdam, The Netherlands \\ 7 MRC Integrative Epidemiology Unit, Population Health Sciences, Bristol Medical School, University of \\ Bristol, Bristol BS8 2BN, UK; matthew.suderman@bristol.ac.uk (M.S.); caroline.relton@bristol.ac.uk (C.L.R.) \\ 8 MRC Lifecourse Epidemiology Unit, University of Southampton, Southampton General Hospital \\ Southampton, Southampton SO16 6YD, UK; src@mrc.soton.ac.uk (S.R.C.); nch@mrc.soton.ac.uk (N.C.H.); \\ cc@mrc.soton.ac.uk (C.C.) \\ 9 NIHR Southampton Biomedical Research Centre, University of Southampton and University Hospital \\ Southampton NHS Foundation Trust, Southampton SO16 6YD, UK \\ 10 NIHR Oxford Biomedical Research Centre, University of Oxford, Oxford OX1 2JD, UK \\ 11 UCD Perinatal Research Centre, School of Medicine, University College Dublin, National Maternity \\ Hospital, Dublin 2, Ireland; fionnuala.mcauliffe@ucd.ie \\ 12 Singapore Institute for Clinical Sciences (SICS), Agency for Science, Technology and Research (A*STAR), \\ 117609 Singapore, Singapore \\ * Correspondence: barbara.heude@inserm.fr \\ + The authors contributed equally to this article.
}

Received: 10 October 2019; Accepted: 4 November 2019; Published: 8 November 2019

\begin{abstract}
The ALPHABET consortium aims to examine the interplays between maternal diet quality, epigenetics and offspring health in seven pregnancy/birth cohorts from five European countries. We aimed to use the Dietary Approaches to Stop Hypertension (DASH) score to assess diet quality, but different versions have been published. To derive a single DASH score allowing cross-country, cross-cohort and cross-period comparison and limiting data heterogeneity within the ALPHABET consortium, we harmonised food frequency questionnaire (FFQ) data collected before and during pregnancy in $\geq 26,500$ women. Although FFQs differed strongly in length and content, we derived a consortium DASH score composed of eight food components by combining the prescriptive
\end{abstract}


original DASH and the DASH described by Fung et al. Statistical issues tied to the nature of the FFQs led us to re-classify two food groups (grains and dairy products). Most DASH food components exhibited pronounced between-cohort variability, including non-full-fat dairy products (median intake ranging from 0.1 to 2.2 servings/day), sugar-sweetened beverages/sweets/added sugars (0.3-1.7 servings/day), fruits (1.1-3.1 servings/day), and vegetables (1.5-3.6 servings/day). We successfully developed a harmonized DASH score adapted to all cohorts being part of the ALPHABET consortium. This methodological work may benefit other research teams in adapting the DASH to their study's specificities.

Keywords: DASH (Dietary Approaches to Stop Hypertension); diet; nutrition; pregnancy

\section{Introduction}

The Developmental Origins of Health and Disease $(\mathrm{DOHaD})$ paradigm suggests that environmental exposures during critical periods of early life development, even before conception, may influence later health in childhood and adulthood [1,2]. It has been established that maternal diet is an important early-life exposure and determinant of both maternal, neonatal and child health outcomes [3]. Indeed, interventional and observational studies have highlighted the role of certain macronutrients, micronutrients, and vitamins on pregnancy complications (e.g., decreased risk of pre-eclampsia), birth outcomes (e.g., decreased risk of preterm birth and low birth weight), and offspring health and growth (e.g., obesity, respiratory health and neurocognitive development) [4-9]. Despite extensive research on the potential importance of maternal intakes of individual nutrients and food groups, looking at dietary quality holistically based on whole diet can improve applicability for public health messaging, since people do not consume nutrients in isolation.

Several scales or indices have been proposed to measure diet quality, and among them the Dietary Approaches to Stop Hypertension (DASH) score is commonly used. Indeed, numerous studies have related the adherence to a DASH diet to several health outcomes such as cardiovascular and metabolic disorders [10-12], cancers [13] or weight management [14]. For instance, a meta-analysis on cardiovascular risk factors concluded that the DASH diet was "an effective nutritional strategy to prevent cardiovascular diseases" [15]. Specifically, among pregnant women with complications such as gestational or chronic hypertension and gestational diabetes mellitus, favouring a DASH diet can be a potential strategy for improving pregnancy outcomes [16,17]. However, among women without pregnancy complications, the protective effects of the DASH diet against risk of adverse pregnancy and birth outcomes are inconsistent, warranting further research in general pregnant populations [18].

Gathering data from seven mother-child cohorts from five European countries, the ALPHABET consortium aims to expand the knowledge base regarding the interplay between maternal diet quality (defined by the DASH score), dietary inflammation (defined by the dietary inflammatory index [19]), epigenetics (DNA methylation), and offspring health (adiposity, bone, cardiometabolic, respiratory and neurodevelopmental health) and identify biomarkers that may inform future public health strategies. To examine these research questions, the DASH score, used to assess maternal dietary quality, needs to be derived in a harmonised way for the seven ALPHABET cohorts to reduce heterogeneity. The harmonisation is important because even though it is common to assess dietary intake through food frequency questionnaires (FFQ) in epidemiological studies, these questionnaires can differ in structure and length from one cohort to the other. Some studies have successfully achieved post hoc standardisation of dietary data from diverse sources and cohorts [20,21]. Furthermore, several variants of DASH index derivation methods have been published, with notable differences in the food components included and the scoring criteria $[15,16]$. No consensus exists but the most commonly used DASH score method is the one proposed by Fung et al. [10], which ranks participants based on quintiles of dietary intakes. 
In this context, the present work aims to (1) explain the method used to derive a harmonised DASH score in the ALPHABET consortium and detail the challenges encountered during this process and (2) describe the maternal DASH score and related food consumption in different cohorts and over three periods of assessment: pre-pregnancy, early pregnancy, and late pregnancy.

\section{Materials and Methods}

\subsection{Study Populations}

The ALPHABET project is a European consortium comprised of seven longitudinal birth cohort studies: the Avon Longitudinal Study of Parents and Children (ALSPAC), the study on the preand early postnatal determinants of child health and development (EDEN), the Generation R Study (Generation R), the Lifeways Cross-Generation Cohort Study (Lifeways), the Polish Mother and Child Cohort (REPRO_PL), the Randomised Control Trial of Low Glycaemic Index Diet study (ROLO), and the Southampton Women's Survey (SWS). Details on study designs and sample sizes of these cohorts are available elsewhere [22-30].

Descriptive characteristics of each of the cohorts within the ALPHABET consortium are presented in Table 1. Of the seven included studies, two were based in Ireland, two in England, and one each in Poland, the Netherlands, and France. Most women were recruited during pregnancy, except for SWS where recruitment commenced before pregnancy. Started in 1990, ALSPAC was the oldest study, whereas REPRO_PL and ROLO, both started in 2007, were the most recent. The sample size ranged from 759 (ROLO) to 14,541 (ALSPAC). Since all studies assessed maternal diet with FFQs at times which differed between cohorts, we categorised into three periods: pre-pregnancy, early pregnancy (1st or 2nd trimester) and late pregnancy (3rd trimester).

All participating cohorts have obtained the relevant institutional ethical approval and research to date has been conducted according to the guidelines laid down in the Declaration of Helsinki.

\subsection{Dietary Data Collection and Treatment}

Women completed mostly validated (except ALSPAC), semi-quantitative (EDEN [31], Generation R [32], Lifeways [33,34], ROLO [34,35]), or non-quantitative (ALSPAC [36], REPRO_PL [28], SWS [37]) FFQs, which were designed to assess average dietary intake over pre-conception or pregnancy periods (Table 1). Women declared food intake on frequency scales ranging from five (in ALSPAC) to nine response categories (in Generation R, Lifeways and ROLO) (Table S1). An item "not ticked" (missing) was considered as "non-consuming" and imputed with zero, assuming that these mothers did not eat it. All food consumption frequencies were converted into daily frequencies (servings per day) to be comparable across cohorts. For cohorts with semi-quantitative FFQs, we also calculated food consumption data in amounts (grams and millilitres per day).

\subsection{DASH Score Creation}

Several DASH scores have been developed or adapted in the literature, which differ regarding both the food components included and scoring method [38]. The DASH diet was initially created to help reduce arterial hypertension but no consensus exists on how to generate DASH scores from FFQs [39]. To our knowledge, the DASH index proposed by Fung et al. [10] has been the most widely used. Therefore, we generated DASH scores, using the Fung method, from the data collected within each of the ALPHABET consortium cohorts and adapted to their specificities as described below. Previously published DASH scores were based on whether one meets a recommended minimum number of servings [40]. In contrast, Fung's DASH index relies on quintile ranking, allowing for a wider, more-discriminating score range [38], an approach that we judged more appropriate for ALPHABET considering the diversity of cohorts, time periods, and FFQs used. Because the main purpose of a FFQ is to rank participants according to their reported intakes rather than estimation of absolute intakes (sodium in particular is not estimated well with FFQ), scoring by quintiles would be less prone to misclassification [10]. 
Table 1. Characteristics of the cohorts in the ALPHABET consortium.

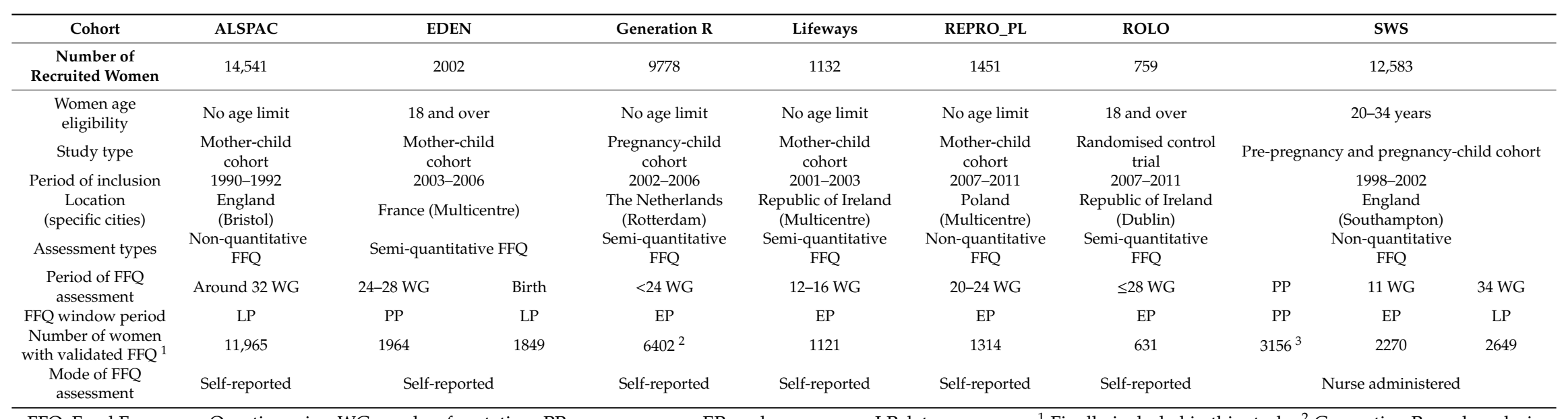

FFQ: Food Frequency Questionnaire. WG: weeks of gestation. PP: pre-pregnancy, EP: early pregnancy, LP: late pregnancy. ${ }^{1}$ Finally included in this study. ${ }^{2}$ Generation R used a caloric cut-off to exclude women with caloric intakes $<500 \mathrm{kcal}$ or $>3500 \mathrm{kcal}$ (all other cohorts did not make any exclusion based on energy before deriving the DASH score). ${ }^{3} 12,572$ women answered the FFQ at PP period but only 3158 women went on to have live singleton birth within the study. 


\subsubsection{Food Group Classification and Item Selections}

To select food groups and to classify food items into food components, we referred to the Fung's DASH [10], the original "DASH Eating Plan" [41] and the Eurocode 2 [42]. Table 2 presents an inventory of the number of food items available by food component between cohorts, based on food components included in the Fung's DASH or the original "DASH Eating Plan". As illustrated, the details for dietary data differed across the ALPHABET consortium cohorts. The number of FFQ items ranged from 43 to almost 300. The ALSPAC FFQ included less than 8 food items within each food component. In contrast, the Generation R questionnaire included more than 8 food items for most food groups (except for sugar-sweetened beverages). The number of items varied also according to food components: vegetables (mean $=18.6)$, fruits $($ mean $=11.9)$, and red and processed meats $($ mean $=12.0)$ were generally assessed by more than 11 food items, while whole grains (mean $=5.3$ ) and low-fat dairy products (mean $=4.3$ ) food component were assessed through a much smaller number of items. A food component with a limited number of items included may result in statistical distributions that are less able to discriminate participants from each other. Therefore, we inventoried all relevant food items in all cohorts and examined all food component distributions.

\subsubsection{Scoring Method}

For each food component, consumption frequency was divided into quintiles within each cohort, and participants were then classified according to their intake ranking. Consumption of food components with a high recommended intake was rated on a scale from 1 to 5 using their quintile number such that participants in Quintile 1 (lowest consumption) received a score of 1 , and those in Quintile 5 (highest consumption) received a score of 5 . Conversely, dietary components with a low recommended intake were scored on a reverse scale with lower consumption receiving a higher score. Finally, component scores were summed up and an overall DASH score for each participant was calculated. A higher score characterizes a higher dietary quality.

\subsection{Statistical Analyses}

The different DASH food component consumption (in frequencies and/or amounts) were described for each cohort and time period (pre-pregnancy, early pregnancy and late pregnancy) using the median (interquartile range, IQR) and compared graphically using the quintiles of the distributions. Spearman's correlations were calculated for both DASH scores based on frequencies with those based on amounts (for cohorts with data available for both units). All analyses were carried out with SAS software v9.4 (SAS Institute Inc, Cary, North Carolina, USA) and RStudio was used to generate the figures. 
Table 2. Availability of FFQ data for each cohort.

\begin{tabular}{|c|c|c|c|c|c|c|c|c|}
\hline Cohort & ALSPAC & EDEN & $\begin{array}{c}\text { Generation } \\
\mathbf{R}\end{array}$ & Lifeways & REPRO_PL & ROLO & SWS & ALPHABET $^{1}$ \\
\hline FFQ total of food items & 43 & 137 & 293 & 158 & 66 & 158 & 104 & 137.0 \\
\hline $\begin{array}{l}\text { FFQ total of food items } \\
\text { without alcohol }\end{array}$ & 43 & 130 & 283 & 154 & 62 & 154 & 99 & 132.1 \\
\hline $\begin{array}{c}\text { Total of food items selected } \\
\text { for the DASH }\end{array}$ & 34 & 65 & 136 & 85 & 36 & 85 & 58 & 71.3 \\
\hline $\begin{array}{c}\%{ }^{2} \text { items selected/total food } \\
\text { items without alcohol }\end{array}$ & $79.1 \%$ & $50.0 \%$ & $48.1 \%$ & $55.2 \%$ & $58.1 \%$ & $55.2 \%$ & $58.6 \%$ & $57.8 \%$ \\
\hline \multicolumn{9}{|c|}{ Food components with higher intakes recommended } \\
\hline Whole grains & 3 & 1 & 13 & 7 & 2 & 7 & 4 & 5.3 \\
\hline Total grains ${ }^{3}$ & 7 & 7 & 20 & 14 & 5 & 14 & 8 & 10.7 \\
\hline Vegetables & 5 & 16 & 33 & 24 & 12 & 24 & 16 & 18.6 \\
\hline Fruits & 3 & 12 & 20 & 13 & 10 & 13 & 12 & 11.9 \\
\hline Low-fat dairy products & 2 & 4 & $10^{4}$ & 6 & 0 & 6 & 2 & 4.3 \\
\hline Non-full-fat dairy products ${ }^{3}$ & 3 & 6 & $18^{4}$ & 7 & 2 & 7 & 5 & 6.9 \\
\hline Lean meats, poultry, fish & 4 & 9 & 10 & 9 & 13 & 9 & 5 & 8.4 \\
\hline Nuts, seeds, legumes & 7 & 4 & 14 & 5 & 2 & 5 & 2 & 5.6 \\
\hline \multicolumn{9}{|c|}{ Food components with lower intakes recommended } \\
\hline Fats and oils & 5 & 10 & 13 & 15 & 2 & 15 & 11 & 10.1 \\
\hline Sweets and added sugars & 3 & 5 & 9 & 4 & 1 & 4 & 3 & 4.1 \\
\hline Sugar-sweetened beverages & 2 & 3 & 2 & 1 & 0 & 1 & 2 & 1.6 \\
\hline Red and Processed meat & 4 & 12 & 20 & 17 & 4 & 17 & 10 & 12.0 \\
\hline Sodium & $\begin{array}{l}\text { Available in } \\
\text { grams/day }\end{array}$ & $\begin{array}{l}\text { Available in } \\
\text { grams/day }\end{array}$ & $\begin{array}{l}\text { Available in } \\
\text { grams/day }\end{array}$ & $\begin{array}{l}\text { Available in } \\
\text { grams/day }\end{array}$ & $\begin{array}{l}\text { Available in } \\
\text { grams/day }\end{array}$ & $\begin{array}{l}\text { Available in } \\
\text { grams/day }\end{array}$ & $\begin{array}{l}\text { Available in } \\
\text { grams/day }\end{array}$ & $\begin{array}{l}\text { Available in } \\
\text { grams/day }\end{array}$ \\
\hline
\end{tabular}




\section{Results}

\subsection{DASH Creation Choices-Food Components and Items Retained}

Two food components, i.e., whole grain and low-fat dairy products consist of a low number of food items, a low number of response categories and a high number of non-consumers. For illustration purposes, Figure 1A displays the distributions of whole grains and total grains in the EDEN cohort, and Figure 1B displays the distributions of low-fat and non-full-fat dairy product components in the SWS cohort. Quintiles cannot be derived from such distributions and would not permit generation of a continuous score. Consequently, we reconsidered the whole grains and low-fat dairy products food component from the Fung's DASH score into total grains and non-full-fat dairy products. Finally, the DASH score we developed within the seven cohorts of the ALPHABET consortium was composed of eight food components (seven food groups and one nutrient) (Table 3). For more details, Table S2 summarizes the included and excluded foods for each food component composing the DASH score and the corresponding score criteria. A high score corresponds to high intakes of total grains, vegetables (excluding potatoes and condiments), fruits, non-full-fat dairy products, and nuts/seeds/legumes, and low intakes of red and processed meats, sugar-sweetened beverages/sweets/added sugars, and sodium. Adapted to ALPHABET's specificities, this DASH score was a composite score ranking from 8 to 40 points. As displayed in Table 2, we used 48.1\% (Generation R) to 79.1\% (ALSPAC) of the total FFQ food items (excluding alcohol) for creating the DASH score (ALPHABET consortium mean $=57.8 \%$ ).

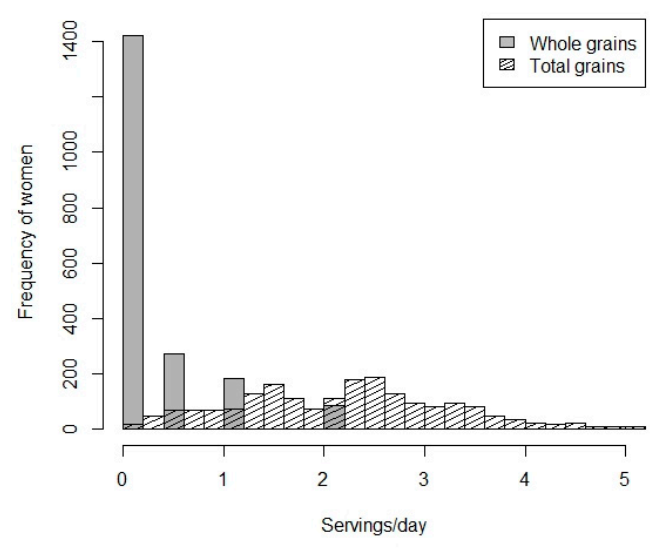

(A)

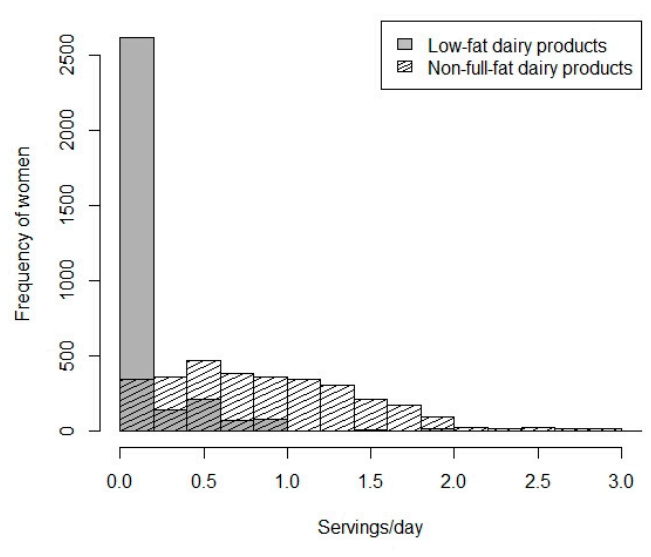

(B)

Figure 1. Distributions of servings/day (at pre-pregnancy period) between (A) whole grains and total grains in EDEN; and (B) low-fat and non-full-fat dairy products in SWS. 
Table 3. Final food component choices.

\begin{tabular}{|c|c|c|c|}
\hline Fung's DASH Components & Original DASH Components & $\begin{array}{l}\text { Food Components Selected } \\
\text { in ALPHABET }\end{array}$ & Rationale \\
\hline Whole grains & $\begin{array}{l}\text { Total grains (Additional note: "whole grains } \\
\text { are recommended for most grain servings as a } \\
\text { good source of fiber and nutrients") }\end{array}$ & Total grains & $\begin{array}{l}\text { - Consumption of grains is not explicitly limited by some public health } \\
\text { organizations (e.g., PNNS }{ }^{1} \text { in France [43,44]) and some diet score are } \\
\text { considering total grains (e.g., several Mediterranean diet [45]). } \\
\text { - The original DASH considers grains as a food component (foster } \\
\text { whole grains are recommended as additional note only) [41]. } \\
\text { - Lack of information on whole grains in several ALPHABET cohorts } \\
\text { (depending on FFQ length and detail) (e.g., EDEN has } 7 \text { items for } \\
\text { total grains but a single item for whole grains). }\end{array}$ \\
\hline Vegetables without potatoes & Vegetables & $\begin{array}{l}\text { Vegetables (excluding potatoes } \\
\text { and condiments) }\end{array}$ & $\begin{array}{l}\text { - Potatoes are not considered as vegetables according to } \\
\text { Eurocode } 2 \text { [42]. } \\
\text { By using servings/day, including condiments would generate an } \\
\text { overestimation of the consumption. }\end{array}$ \\
\hline Fruits & Fruits & Fruits & Not applicable \\
\hline Low-fat dairy products & Low-fat milks \& milk products & Non-full-fat dairy products & $\begin{array}{l}\text { - } \quad \text { Some diet scores do consider total dairy products [40]. } \\
\text { Equivocal scientific justification: "the recommendation to focus on low-fat } \\
\text { in place of regular-and high-fat dairy is currently not evidence-based" [46] } \\
\text { Lack of information on low-fat dairy products in several ALPHABBT } \\
\text { cohorts (e.g., REPRO_PL does not have variables for low-fat } \\
\text { dairy products). }\end{array}$ \\
\hline Nuts, seeds, legumes & Nuts, seeds, legumes & Nuts, seeds, legumes & Not applicable \\
\hline \multirow{2}{*}{ Red and processed meats } & Lean meat, poultry, fish & \multirow{2}{*}{ Red and processed meats } & \multirow{2}{*}{ Not applicable } \\
\hline & Fats and oils & & \\
\hline Sugar-sweetened beverages & Sweets and added sugars & $\begin{array}{l}\text { Sugar-sweetened beverages, } \\
\text { sweets, and added sugars }\end{array}$ & $\begin{array}{l}\text { - Take into Nuts, seeds, legumes account a wider diversity of } \\
\text { sugar sources. }\end{array}$ \\
\hline Sodium & Additional note for reducing salt & Sodium & Not applicable \\
\hline
\end{tabular}

FFQ: Food Frequency Questionnaire. ${ }^{1}$ PNNS: Programme National Nutrition Santé (French National Nutrition and Health Program). 


\subsection{DASH Scores and Intakes of DASH Food Groups}

By construct, mean (SD) DASH scores centred around 24 (median value between 8 and 40): from 23.7 (4.6) points (Lifeways' score at early pregnancy from frequencies) to 24.1 (4.3) points (SWS' score at early pregnancy from frequencies). Spearman's correlation coefficients (rho $(95 \% \mathrm{CI}))$ between DASH scores from frequencies and amounts were consistently very high: from $0.88(0.86,0.89)$ for ROLO to $0.92(0.91,0.93)$ for Lifeways, both at early pregnancy (Table S3).

Table 4 presents median intakes of selected food components of the DASH score cohort and period. Consumption of nuts/seeds/legumes was relatively similar between cohorts: median values were between 0.1 and 0.3 servings/day. Other food component consumption displayed more between-cohort variability: total grains ranged from 1.6 to 3.5 servings/day, vegetables (excluding potatoes and condiments) from 1.5 to 3.6 servings/day, fruits from 1.1 to 3.1 servings/day, non-full-fat dairy products from 0.1 to 2.2 servings/day (or 18 to 417 grams/day in cohorts with data available in amounts), red and processed meats from 0.4 to 1.0 servings/day, sugar-sweetened beverages/sweets/added sugars from 0.3 to 1.7 servings/day, and lastly sodium ranged from 2.2 to 3.3 grams/day.

The daily food component intake frequencies corresponding to the quintiles of the distributions for every DASH component (except sodium consumption which are presented as grams/day) are displayed in Figure 2. Some differences in quintile distributions were observed between cohorts. For instance, for vegetables (excluding potatoes and condiments) intake, frequency consumption of quintiles 2-4 (20th to 80th percentile) ranged from 0.7 to 2.7 servings/day in EDEN and 0.9 to 2.0 servings/day in ALSPAC, which are noticeably lower than those observed in other cohorts e.g., 2.2-5.5 servings/day in ROLO. Another example is non-full-fat dairy products, for which frequency consumption of quintiles 2-4 (20th to 80th percentile) ranged from 0.1 to $1.1,1.0$ to 1.4 , and 1.2 to 3.4 servings/day in Lifeways, ALSPAC and EDEN (during late pregnancy), respectively. Conversely, other food components (e.g., fruits, red and processed meats, sodium) varied less among cohorts. 
Table 4. Median intakes of DASH food components by cohort and period in the ALPHABET consortium.

\begin{tabular}{|c|c|c|c|c|c|c|c|c|c|c|c|c|c|c|c|c|c|c|c|c|}
\hline & \multicolumn{2}{|c|}{$\begin{array}{c}\text { ALSPAC } \\
\text { LP } \\
\text { Median[IQR] }\end{array}$} & \multicolumn{2}{|c|}{$\begin{array}{c}\text { PP } \\
\text { Median[IQR] }\end{array}$} & \multicolumn{2}{|c|}{$\begin{array}{c}\text { LP } \\
\text { Median[IQR] }\end{array}$} & \multicolumn{2}{|c|}{$\begin{array}{c}\text { Generation R } \\
\text { EP } \\
\text { Median[IQR] }\end{array}$} & \multicolumn{2}{|c|}{$\begin{array}{c}\text { Lifeways } \\
\text { EP } \\
\text { Median[IQR] }\end{array}$} & \multicolumn{2}{|c|}{$\begin{array}{c}\text { REPRO_PL } \\
\text { EP } \\
\text { Median[IQR] }\end{array}$} & \multicolumn{2}{|c|}{$\begin{array}{c}\text { ROLO } \\
\text { EP } \\
\text { Median[IQR] }\end{array}$} & \multicolumn{4}{|c|}{$\begin{array}{c}\text { SWS } \\
\text { EP } \\
\text { Median[IQR] } \\
\end{array}$} & \multicolumn{2}{|c|}{$\begin{array}{c}\text { LP } \\
\text { Median[IQR] }\end{array}$} \\
\hline & & & & & & & & & & al grains & & & & & & & & & & \\
\hline $\mathrm{f} / \mathrm{d}^{1}$ & 3.4 & [1.4] & 2.3 & [1.5] & 2.5 & [1.7] & - & - & 3.2 & [2.7] & 1.6 & {$[0.7]$} & 2.8 & [2.3] & 3.4 & [1.9] & 3.5 & [2.0] & 3.5 & [1.7] \\
\hline $\mathrm{g} / \mathrm{d}^{2}$ & 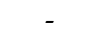 & 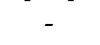 & 142 & [89] & 149 & [91] & 162 & [104] & 162 & [138] & - & - & 183 & [136] & - & - & - & - & - & - \\
\hline \multicolumn{21}{|c|}{ Vegetables (excluding potatoes and condiments) } \\
\hline $\mathrm{f} / \mathrm{d}$ & 1.5 & [0.9] & 1.6 & [1.6] & 1.5 & [1.4] & - & - & 3.0 & {$[2.5]$} & 2.5 & {$[1.8]$} & 3.6 & 2.4] & 2.9 & [1.9] & 2.6 & {$[1.8]$} & 2.6 & {$[1.7]$} \\
\hline $\mathrm{g} / \mathrm{d}$ & 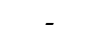 & 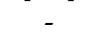 & 176 & [201] & 154 & [167] & 147 & [89] & 269 & [222] & - & . & 332 & [224] & - & 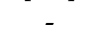 & - & . & - & - \\
\hline \multicolumn{21}{|c|}{ Fruits } \\
\hline $\mathrm{f} / \mathrm{d}$ & 1.1 & [1.1] & 1.7 & [2.0] & 1.7 & [2.1] & - & - & 2.8 & [2.7] & 2.2 & [1.4] & 3.1 & [2.5] & 2.1 & [2.0] & 2.5 & [2.2] & 2.7 & {$[2.5]$} \\
\hline $\mathrm{g} / \mathrm{d}$ & - & - & 311 & [353] & 293 & [385] & 285 & [264] & 340 & [327] & - & - & 360 & [291] & - & - & - & - & - & - \\
\hline \multicolumn{21}{|c|}{ Non-full-fat dairy products } \\
\hline $\mathrm{f} / \mathrm{d}$ & 1.3 & [0.3] & 1.6 & [1.5] & 2.2 & [1.8] & - & - & 0.1 & [1.0] & 1.0 & {$[0.7]$} & 1.0 & [1.4] & 0.8 & [0.7] & 0.8 & {$[0.8]$} & 1.0 & [1.0] \\
\hline $\mathrm{g} / \mathrm{d}$ & - & - & 303 & [357] & 417 & [403] & 224 & [308] & 18 & [198] & - & - & 250 & [298] & - & - & - & - & - & - \\
\hline \multicolumn{21}{|c|}{ Nuts, seeds, legumes } \\
\hline $\mathrm{f} / \mathrm{d}$ & 0.3 & [0.3] & 0.1 & [0.1] & 0.1 & [0.1] & - & - & 0.2 & [0.3] & 0.1 & {$[0.3]$} & 0.2 & [0.4] & 0.2 & {$[0.2]$} & 0.2 & {$[0.2]$} & 0.2 & {$[0.2]$} \\
\hline $\mathrm{g} / \mathrm{d}$ & - & - & 13 & [16] & 10 & [17] & 13 & [19] & 19 & [49] & - & - & 19 & [21] & - & - & - & - & - & - \\
\hline \multicolumn{21}{|c|}{ Red and processed meats } \\
\hline $\mathrm{f} / \mathrm{d}$ & 0.4 & [0.3] & 0.7 & [0.6] & 0.7 & [0.5] & - & - & 0.9 & {$[0.8]$} & 1.0 & {$[0.7]$} & 0.9 & [0.8] & 0.7 & {$[0.7]$} & 0.7 & {$[0.6]$} & 0.7 & {$[0.7]$} \\
\hline $\mathrm{g} / \mathrm{d}$ & - & 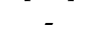 & 61 & [57] & 60 & [55] & 51 & [44] & 87 & {$[66]$} & - & - & 87 & [67] & - & - & - & - & - & - \\
\hline \multicolumn{21}{|c|}{ Sugar-sweetened beverages, sweets, and added sugars } \\
\hline $\mathrm{f} / \mathrm{d}$ & 0.4 & [0.8] & 1.2 & [1.9] & 1.3 & [2.3] & - & - & 1.1 & [1.9] & 0.3 & {$[0.2]$} & 0.9 & [1.4] & 1.2 & [3.8] & 1.2 & [3.1] & 1.7 & {$[3.8]$} \\
\hline $\mathrm{g} / \mathrm{d}$ & - & - & 49 & [153] & 55 & [187] & 67 & [110] & 46 & [101] & - & - & 28 & [66] & - & - & - & - & - & - \\
\hline \multicolumn{21}{|c|}{ Sodium } \\
\hline $\mathrm{mg} / \mathrm{d}$ & 2161 & [854] & 2871 & [1636] & 2831 & [1461] & 3324 & [1298] & 3001 & [1512] & 2163 & [704] & 2883 & [1381] & 3142 & [1188] & 3246 & [1211] & 3294 & [1157] \\
\hline
\end{tabular}

PP: pre-pregnancy, EP: early pregnancy, LP: late pregnancy. IQR: Interquartile range. -: not available. ${ }^{1} \mathrm{f} / \mathrm{d}$ : daily frequency in servings per day (rounded to one decimal place). ${ }^{2} \mathrm{~g} / \mathrm{d}$ : daily amount in grams and/or millilitres per day (rounded to the nearest whole number). $\mathrm{mg} / \mathrm{d}$ : daily amount in milligrams per day (rounded to the nearest whole number). 

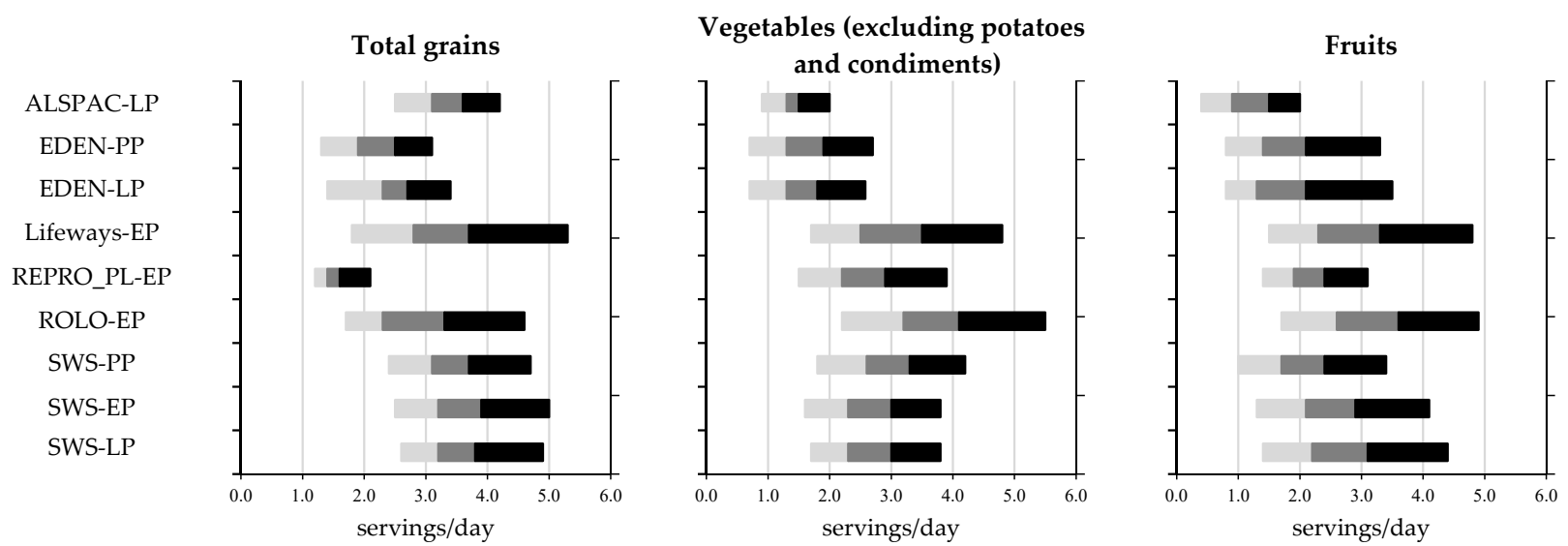

Non-full-fat dairy products

Nuts, seeds and legumes

Red and processed meats

Sugar-sweetened beverages,
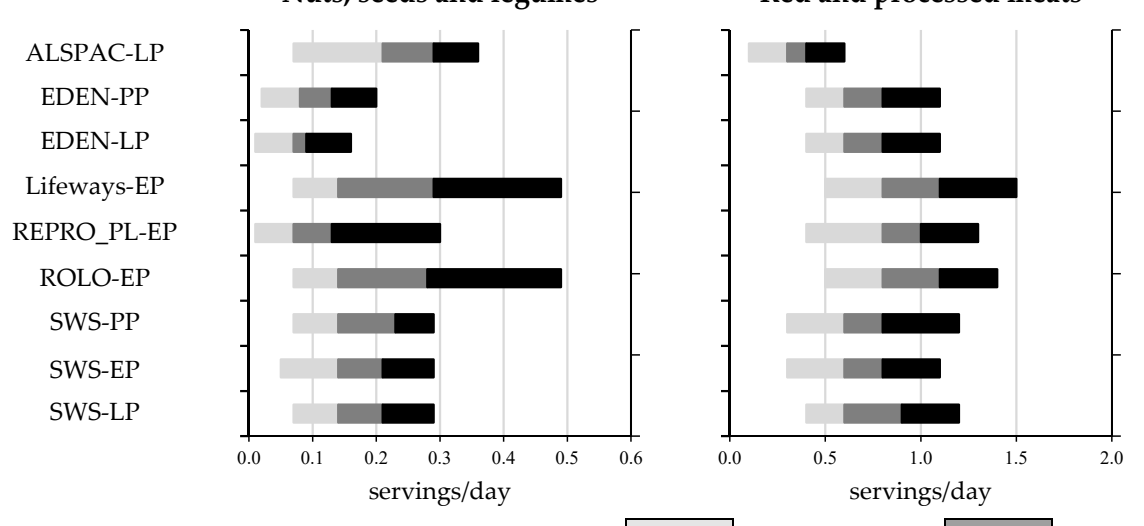

sweets and added sugars
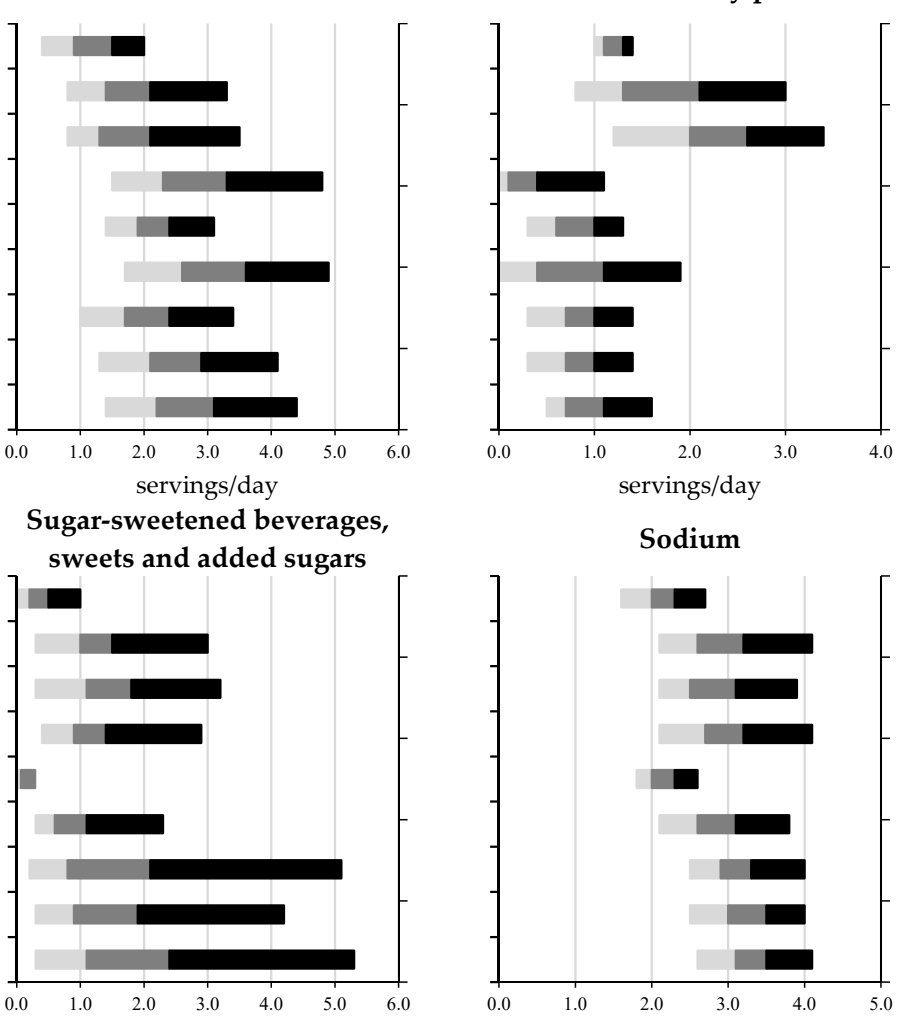

Sodium

Quintile 2

$<$

Quintile 3

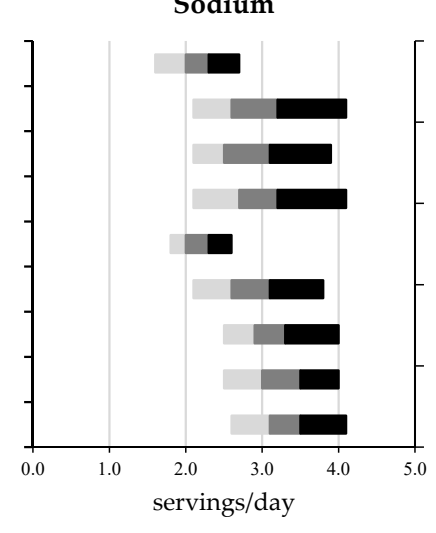

Figure 2. Maternal daily frequency consumption (in quintile) of the eight DASH food components by time point and cohort ${ }^{1}$ in ALPHABET. PP: pre-pregnancy, EP: early pregnancy, LP: late pregnancy. Generation $\mathrm{R}$ data are only available in amount and thus not presented. ${ }^{1}$ The quintiles 1 and 5 spread from the minimum to the quintile 2 limit and from the quintile 4 limit to the maximum, respectively. Maximum observed is likely to exceed $\mathrm{x}$-abscissa and is not necessary the maximum presented in abscissa axis. 


\section{Discussion}

We derived DASH scores for pregnant women from seven European birth cohorts after harmonising data from FFQs of various lengths and degrees of detail. We encountered scientific and methodological issues that led us to adapt previously published DASH scores to specificities of the cohorts included in the ALPHABET consortium. The DASH score that we developed relied on eight food components and ranged from 8 to 40 points. A higher score characterizes a higher dietary quality.

\subsection{Harmonisation Process Choices}

Several studies have previously successfully harmonised dietary data from diverse sources and cohorts [20,21,47-50], demonstrating that retrospective harmonisation is possible. To the best of our knowledge, our study was the first to derive a DASH score from FFQs of different lengths and details across multiple distinct cohorts. Harmonising data was, however, not without challenges.

First, several versions of the DASH score have been used in the literature with large differences in food components included and in scoring criteria [38,39]. Indeed, some published indices were nutrient-based [51] while others had a food group-based approach that considered eight [10], nine [52], ten [53] or eleven [54] distinct food groups. Furthermore differences exist in the way scores were calculated, by comparing food group consumption to dietary guidelines (minimum or maximum intakes) [40] vs. within-study population distribution ranked into quintiles [10]. These methodological discrepancies might be explained by the fact that the DASH score was originally developed in the U.S. as a diet plan for intervention studies or preventive strategies $[41,55,56]$ and was not specifically designed to describe dietary habits in other countries nor for epidemiological observational studies where diet is assessed using FFQs.

Second, the number of available food items and frequency scale categories of some food components resulted in a lack of data variability in some of our cohorts, complicating the derivation of balanced quintiles for whole grains and low-fat dairy products. To overcome this, we redefined whole grains as total grains and low-fat dairy products as non-full-fat dairy products. Although this resulted in slight deviations from the original DASH guidelines, we argue that it is supported by a sound rationale (Table 3). Both diverse public health recommendations and diet scores do not have the same restrictions concerning grains and dairy products [35,53-56]. Moreover, consumption of whole grains and low-fat dairy products, and thus detail of FFQs, may depend on both the cultural [57,58] and generational $[57,59,60]$ habits. Lastly, a statistical requirement was needed to discriminate consumption. Indeed, had we adhered to Fung's classification of food components proposed previously [10], the low number of food items included in some food components, the number of response categories, and the high number of non-consumers would have resulted in non-discriminating consumption frequencies for several cohorts.

\subsection{Daily Frequency Consumption}

Besides some differences between cohorts, consumption of each food component seems to be comparable with those reported in previous literature. The European Prospective Investigation into Cancer and Nutrition (EPIC) reported overall similar consumption of most food groups in France, Netherlands, and United Kingdom as we observed in the ALPHABET consortium cohort studies. For example, in EPIC the recorded mean consumption of vegetables, fruits, and red and processed meats was 128-261, 170-274, and 50-78 g/day respectively [61,62], we observe median consumption of 147-332, 285-360, and 51-87 g/day for the same food groups in the ALPHABET consortium cohorts. Within the Australian Longitudinal Study on Women's Health, a country with a Western culture and presumably similar dietary habits, median intake values of breads/cereals, fruits, vegetables and dairy were 2.6, 2.2, 2.1, and 2.0 servings/day, respectively [63]. These values are comparable with those in the ALPHABET consortium cohorts: median intakes range from 1.6 to 3.5 servings/day for total grains, from 1.1 to 3.1 servings/day for fruits, from 1.5 to 3.0 servings/day for vegetables (excluding 
potatoes and condiments), and from 0.8 to 2.2 servings/day (except Lifeways with 0.1 servings/day) for non-full-fat dairy products.

A study comparing four established DASH diet indices (in association with colorectal cancer) suggested that all indices capture an underlying construct inherent in the DASH dietary pattern [38]. A consequence of the quintile-based design used in Fung's scoring system and our DASH score, (determined by the specific cohort distribution of each food component), is that it discriminates individuals within each cohort but not necessarily between cohorts. Hence, identical scores in different cohorts may reflect similar dietary quality but could also arise from differences in FFQ characteristics (diverse lengths and details) across cohorts. Moreover, methodological choices such as caloric exclusion (e.g., Generation R) might generate cohort variability. However, the main aim in this study is to create a DASH score for all cohorts within our consortium using harmonised dietary data to reduce heterogeneity. To this end, the quintile approach is less prone to measurement error (as FFQs were used in all our cohorts) and the resulting cohort-specific DASH score should be a valid tool for intra-cohort ranking of dietary quality, which can be used for cohort-specific association analysis with health outcomes and subsequent meta-analysis.

\subsection{Dietary Data Utilisation}

Each cohort had its own protocol for measuring food intake. Indeed, the FFQs varied in length (from 43 to 293 food items), level of detail (from 5 to 9 response categories), and portion sizes used in the semi-quantitative FFQ (country- or region-specific). Such differences likely result in discrepancies in estimated intake. However, DASH scores incorporate a significant part of each FFQ: 48.1 to $79.1 \%$ of food items included in the FFQs (without alcohol); and the majority of food components comprise a significant number of food items. Indeed, except for a limited number of groups in ALSPAC and REPRO_PL, all food components relied on at least 5 food items. In addition, correlations between DASH scores calculated from frequencies and amounts (for cohorts with data available in both units) were very high. Thus, the method to derive the DASH score is robust and insensitive to country specific cultural habits which could impact portion sizes. Although FFQs have limitations such as recall or reporting biases, most of the FFQs were validated within each cohort in ALPHABET, and are, as already demonstrated in former studies, an appropriate tool to rank women based on energy, nutrients, and food intakes [64-66].

\section{Conclusions}

In conclusion, we developed a DASH score composed of eight food components and adapted to the ALPHABET consortium's specificities. This work was essential for conducting future meta-analyses within the ALPHABET consortium and will permit us to explore the interplay between maternal diet quality, epigenetics, and offspring health. We demonstrated the feasibility of harmonising existing dietary intake data from diverse studies. The explanations of the method used to derive DASH scores and the challenges faced during this process may be useful to guide other researchers in adapting the DASH score to their study's specificities.

Supplementary Materials: The following are available online at http://www.mdpi.com/2072-6643/11/11/2706/s1, Table S1: FFQ frequency scales of the ALPHABET consortium; Table S2: Summary of included and excluded foods for each food components composing the DASH index; Table S3: Spearman's correlation coefficients (rho $(95 \% \mathrm{CI})$ ) between DASH scores from frequencies and amounts, by cohort and period in ALPHABET.

Ethical Approvals: Specific cohort approvals are as follows: ALSPAC: ALSPAC Ethics and Law Committee (IRB00003312) and Local Research Ethics Committees; EDEN: Ethics Committee (CCPPRB) and CNIL (Commission Nationale Informatique et Liberté), the French data privacy institution; Generation R: Medical Ethical Committee of the Erasmus Medical Center, Rotterdam; Lifeways: University College Dublin Research Ethics Committee and St. Vincent's University Hospital Research Ethics Committee; REPRO_PL: Ethical Committee of the Nofer Institute of Occupational Medicine, Łódź, Poland (Decision No. 7/2007); ROLO: Ethics Committee of the National Maternity Hospital, Dublin, Ireland; SWS: Southampton and South West Hampshire Research Ethics Committee, ALSPAC Law and Ethics Committee, and the Local Research Ethics Committees. 
Author Contributions: Conceptualization, A.M.A., A.F., C.M.P., B.H., and J.Y.B.; data curation, A.M.A., A.F., B.d.L.-G., K.P., W.H., A.J., and M.S.; formal analysis, A.M.A. and A.F.; funding acquisition, K.P., W.H., L.D., M.S., C.L.R., N.C.H., C.M.P., and B.H.; investigation, K.P., W.H., L.D., M.S., C.L.R., N.C.H., C.M.P., and B.H.; methodology, A.M.A., A.F., B.H., and J.Y.B.; project administration, C.M.P., B.H., and J.Y.B.; resources, K.P., W.H., L.D., M.S., C.L.R., N.C.H., C.M.P., and B.H.; software, A.M.A., A.F., and B.H.; supervision, B.H. and J.Y.B.; writing-original draft, A.M.A., B.H., and J.Y.B.; writing-review and editing, A.M.A., A.F., B.d.L.-G., L.-W.C., K.P., W.H., A.J., S.M.M.-B., L.D., M.S., C.L.R., S.R.C., N.C.H., C.C., F.M.M., C.C.K., C.M.P., B.H.; and J.Y.B. B.H., and J.Y.B. contributed and supervised equally the work of this article.

Funding: ALPHABET: This research was supported by an award from the European Union's Horizon 2020 research and innovation programme under the ERA-Net Cofund of the Joint Programming Initiative Healthy Diet for Healthy Life (JPI-HDHL) (http://www.healthydietforhealthylife.eu) action number 696295 (Biomarkers for Nutrition and Health). Co-funding was provided by Science Foundation Ireland, Ireland (Grant Number SFI/16/ERA-HDHL/3360), the UK Biotechnology and Biological Sciences Research Council (ERA-HDHL Biomarkers: BBSRC: BB/P028179/1 and BB/P028187/1), the National Centre for Research and Development (ERA-HDHL/01/ALPHABET/1/2017), the ZonMW The Netherlands (no 529051014; 2017)) ALPHABET project (no 696295; 2017), and the French National Agency of Research (reference AnrR16227KK). The APC was funded by the French National Agency of Research (reference AnrR16227KK). ALSPAC: The UK Medical Research Council and Wellcome (Grant ref: 102215/2/13/2) and the University of Bristol provide core support for ALSPAC. This publication is the work of the authors, and Matthew Suderman will serve as guarantor for the contents of this paper. EDEN: The EDEN study was supported by Foundation for medical research (FRM), National Agency for Research (ANR), National Institute for Research in Public health (IRESP: TGIR cohorte santé 2008 program), French Ministry of Health (DGS), French Ministry of Research, INSERM Bone and Joint Diseases National Research (PRO-A), and Human Nutrition National Research Programs, Paris-Sud University, Nestlé, French National Institute for Population Health Surveillance (InVS), French National Institute for Health Education (INPES), the European Union FP7 programmes (FP7/2007-2013, HELIX, ESCAPE, ENRIECO, Medall projects), Diabetes National Research Program (through a collaboration with the French Association of Diabetic Patients (AFD)), French Agency for Environmental Health Safety (now ANSES), Mutuelle Générale de l'Education Nationale a complementary health insurance (MGEN), French national agency for food security, French-speaking association for the study of diabetes and metabolism (ALFEDIAM). Generation R: The Generation R Study is made possible by financial support from the Erasmus Medical Centre, Rotterdam, the Erasmus University Rotterdam, and The Netherlands Organization for Health Research and Development. Dr Liesbeth Duijts received funding from the European Union's Horizon 2020 co-funded programme ERA-Net on Biomarkers for Nutrition and Health (ERA HDHL) (ALPHABET project (no 696295; 2017), ZonMW The Netherlands (no 529051014; 2017)). The project received funding from the European Union's Horizon 2020 research and innovation programme (LIFECYCLE project, grant agreement no 733206; 2016). The study sponsors had no role in the study design, data analysis, interpretation of data, or writing of this report. The Generation R Study is conducted by the Erasmus Medical Centre in close collaboration with the School of Law and the Faculty of Social Sciences at the Erasmus University, Rotterdam, the Municipal Health Service, Rotterdam area, and the Stichting Trombosedienst and Artsenlaboratorium Rijnmond (Star-MDC), Rotterdam. Lifeways: The Lifeways Cross-Generation Cohort Study is funded by the Irish Health Research Board (reference HRC/2007/13) and is overseen by an inter-disciplinary steering group. REPRO_PL: The REPRO_PL cohort was mainly supported by the Ministry of Science and Higher Education, Poland (PBZ-MEiN-/8/2/2006; contract no. K140/P01/2007/1.3.1.1); by the grant PNRF-218-AI-1/07 from Norway through the Norwegian Financial Mechanism within the Polish- Norwegian Research Fund and National Science Centre, Poland (DEC-2014/15/B/NZ7/00998). ROLO: ROLO study is supported by Health Research Board Health Research Centre for Diet and Health Research Ireland and The National Maternity Hospital Medical Fund, and The European Union's Seventh Framework Programme (FP7/2007-2013). SWS: This work was supported by grants from the Medical Research Council, British Heart Foundation, Arthritis Research UK, Food Standards Agency, and the European Union's Seventh Framework (FP7/2007-2013), projects EarlyNutrition and ODIN under grant agreement numbers 289346 and 613977.

Acknowledgments: ALPHABET: Authors acknowledge all investigators working on the ERA-HDHL ALPHABET Project and are grateful to all the participating families in England, France, The Netherlands, Poland, and Republic of Ireland, who take part in this ongoing cohort study. ALSPAC: We are extremely grateful to all the families who took part in this study, the midwives for their help in recruiting them, and the whole ALSPAC team, which includes interviewers, computer and laboratory technicians, clerical workers, research scientists, volunteers, managers, receptionists, and nurses. Please note that the ALSPAC study website contains details of all available data is available through a fully searchable data dictionary and variable search tool (http://www.bristol.ac.uk/alspac/researchers/our-data/). EDEN: The authors thank the EDEN mother-child cohort study group, whose members are I. Annesi-Maesano, J.Y. Bernard, J. Botton, M.A. Charles, P. Dargent-Molina, B. de Lauzon-Guillain, P. Ducimetière, M. de Agostini, B. Foliguet, A. Forhan, X. Fritel, A. Germa, V. Goua, R. Hankard, B. Heude, M. Kaminski, B. Larroquet, N. Lelong, J. Lepeule, G. Magnin, L. Marchand, C. Nabet, F Pierre, R. Slama, M.J. Saurel-Cubizolles, M. Schweitzer, and O. Thiebaugeorges. Generation R: We gratefully acknowledge the contribution of children and their parents, general practitioners, hospitals, midwives, and pharmacies in Rotterdam. Lifeways: We would like to thank all members of the Lifeways cohort for their valuable contribution to the study. The participation of families is much appreciated. REPRO_PL: We gratefully acknowledge the contribution of children and their parents, hospitals, physicians, and midwives. ROLO: We are grateful to the participating mothers, children, and to the research and clinical staff who enabled us recruit this pregnancy and 
birth cohort. SWS: We are grateful to the women of Southampton and their children, who gave their time to take part in this study, and to the research nurses and other staff who collected and processed the data.

Conflicts of Interest: The authors declare no conflict of interest.

\section{References}

1. Godfrey, K.M.; Costello, P.M.; Lillycrop, K.A. The developmental environment, epigenetic biomarkers and long-term health. J. Dev. Orig. Health Dis. 2015, 6, 399-406. [CrossRef]

2. Haugen, A.C.; Schug, T.T.; Collman, G.; Heindel, J.J. Evolution of DOHaD: The impact of environmental health sciences. J. Dev. Orig. Health Dis. 2015, 6, 55-64. [CrossRef]

3. Procter, S.B.; Campbell, C.G. Position of the Academy of Nutrition and Dietetics: Nutrition and lifestyle for a healthy pregnancy outcome. J. Acad. Nutr. Diet. 2014, 114, 1099-1103. [CrossRef] [PubMed]

4. Devereux, G.; Turner, S.W.; Craig, L.C.; McNeill, G.; Martindale, S.; Harbour, P.J.; Helms, P.J.; Seaton, A. Low maternal vitamin $\mathrm{E}$ intake during pregnancy is associated with asthma in 5-year-old children. Am. J. Respir. Crit. Care Med. 2006, 174, 499-507. [CrossRef] [PubMed]

5. Knudsen, V.K.; Orozova-Bekkevold, I.M.; Mikkelsen, T.B.; Wolff, S.; Olsen, S.F. Major dietary patterns in pregnancy and fetal growth. Eur. J. Clin. Nutr. 2008, 62, 463-470. [CrossRef] [PubMed]

6. Abu-Saad, K.; Fraser, D. Maternal nutrition and birth outcomes. Epidemiol. Rev. 2010, 32, 5-25. [CrossRef]

7. Gernand, A.D.; Schulze, K.J.; Stewart, C.P.; West, K.P.; Christian, P. Micronutrient deficiencies in pregnancy worldwide: Health effects and prevention. Nat. Rev. Endocrinol. 2016, 12, 274-289. [CrossRef]

8. Shapiro, A.L.; Kaar, J.L.; Crume, T.L.; Starling, A.P.; Siega-Riz, A.M.; Ringham, B.M.; Glueck, D.H.; Norris, J.M.; Barbour, L.A.; Friedman, J.E.; et al. Maternal diet quality in pregnancy and neonatal adiposity: The Healthy Start Study. Int. J. Obes. 2016, 40, 1056-1062. [CrossRef]

9. Borge, T.C.; Aase, H.; Brantsæter, A.L.; Biele, G. The importance of maternal diet quality during pregnancy on cognitive and behavioural outcomes in children: A systematic review and meta-analysis. BMJ Open. 2017, 7, e016777. [CrossRef]

10. Fung, T.T.; Chiuve, S.E.; McCullough, M.L.; Rexrode, K.M.; Logroscino, G.; Hu, F.B. Adherence to a DASH-style diet and risk of coronary heart disease and stroke in women. Arch. Intern. Med. 2008, 168, 713-720. [CrossRef]

11. Hinderliter, A.L.; Babyak, M.A.; Sherwood, A.; Blumenthal, J.A. The DASH diet and insulin sensitivity. Curr. Hypertens. Rep. 2011, 13, 67-73. [CrossRef] [PubMed]

12. Harrington, J.M.; Fitzgerald, A.P.; Kearney, P.M.; McCarthy, V.J.; Madden, J.; Browne, G.; Dolan, E.; Perry, I.J. DASH diet score and distribution of blood pressure in middle-aged men and women. Am. J. Hypertens. 2013, 26, 1311-1320. [CrossRef] [PubMed]

13. Jones-McLean, E.; Hu, J.; Greene-Finestone, L.S.; de Groh, M. A DASH dietary pattern and the risk of colorectal cancer in Canadian adults. Health Promot. Chronic Dis. Prev. Can. 2015, 35, 12-20. [CrossRef] [PubMed]

14. Berz, J.P.B.; Singer, M.R.; Guo, X.; Daniels, S.R.; Moore, L.L. Use of a DASH Food Group Score to Predict Excess Weight Gain in Adolescent Girls in the National Growth and Health Study. Arch Pediatr. Adolesc. Med. 2011, 165, 540-546. [CrossRef]

15. Siervo, M.; Lara, J.; Chowdhury, S.; Ashor, A.; Oggioni, C.; Mathers, J.C. Effects of the Dietary Approach to Stop Hypertension (DASH) diet on cardiovascular risk factors: A systematic review and meta-analysis. Br. J. Nutr. 2015, 113, 1-15. [CrossRef]

16. Asemi, Z.; Samimi, M.; Tabassi, Z.; Sabihi, S.; Esmaillzadeh, A. A randomized controlled clinical trial investigating the effect of DASH diet on insulin resistance, inflammation, and oxidative stress in gestational diabetes. Nutrition 2013, 29, 619-624. [CrossRef]

17. Jiang, F.; Li, Y.; Xu, P.; Li, J.; Chen, X.; Yu, H.; Gao, B.; Xu, B.; Li, X.; Chen, W. The efficacy of the Dietary Approaches to Stop Hypertension diet with respect to improving pregnancy outcomes in women with hypertensive disorders. J. Hum. Nutr. Diet. 2019. [CrossRef]

18. Fulay, A.P.; Rifas-Shiman, S.L.; Oken, E.; Perng, W. Associations of the dietary approaches to stop hypertension (DASH) diet with pregnancy complications in Project Viva. Eur. J. Clin. Nutr. 2018, 72, 1385. [CrossRef] 
19. Phillips, C.M.; Chen, L.W.; Heude, B.; Bernard, J.Y.; Harvey, N.C.; Duijts, L.; Mensink-Bout, S.M.; Polanska, K.; Mancano, G.; Suderman, M.; et al. Dietary Inflammatory Index and Non-Communicable Disease Risk: A Narrative Review. Nutrients 2019, 11, 1873. [CrossRef]

20. Mendez, M.A.; Kogevinas, M. A comparative analysis of dietary intakes during pregnancy in Europe: A planned pooled analysis of birth cohort studies. Am. J. Clin. Nutr. 2011, 94 (Suppl. 6), 1993S-1999S. [CrossRef]

21. Olsen, S.F.; Eva Birgisdottir, B.; Halldorsson, T.I.; Brantsæter, A.L.; Haugen, M.; Torjusen, H.; Petersen, S.B.; Strøm, M.; Meltzer, H.M. Possibilities and considerations when merging dietary data from the world's two largest pregnancy cohorts: The Danish National Birth Cohort and the Norwegian Mother and Child Cohort Study. Acta Obstet. Gynecol. Scand. 2014, 93, 1131-1140. [CrossRef] [PubMed]

22. Fraser, A.; Macdonald-Wallis, C.; Tilling, K.; Boyd, A.; Golding, J.; Davey Smith, G.; Henderson, J.; Macleod, J.; Molloy, L.; Ness, A.; et al. Cohort Profile: The Avon Longitudinal Study of Parents and Children: ALSPAC mothers cohort. Int. J. Epidemiol. 2013, 42, 97-110. [CrossRef] [PubMed]

23. Boyd, A.; Golding, J.; Macleod, J.; Lawlor, D.A.; Fraser, A.; Henderson, J.; Molloy, L.; Ness, A.; Ring, S.; Davey Smith, G. Cohort Profile: The 'Children of the 90s' - The index offspring of the Avon Longitudinal Study of Parents and Children. Int. J. Epidemiol. 2013, 42, 111-127. [CrossRef] [PubMed]

24. Heude, B.; Forhan, A.; Slama, R.; Douhaud, L.; Bedel, S.; Saurel-Cubizolles, M.J.; Hankard, R.; Thiebaugeorges, O.; De Agostini, M.; Annesi-Maesano, I.; et al. Cohort Profile: The EDEN mother-child cohort on the prenatal and early postnatal determinants of child health and development. Int. J. Epidemiol. 2016, 45, 353-363. [CrossRef] [PubMed]

25. Kooijman, M.N.; Kruithof, C.J.; van Duijn, C.M.; Duijts, L.; Franco, O.H.; van IJzendoorn, M.H.; de Jongste, J.C.; Klaver, C.C.; van der Lugt, A.; Mackenbach, J.P.; et al. The Generation R Study: Design and cohort update 2017. Eur. J. Epidemiol. 2016, 31, 1243-1264. [CrossRef] [PubMed]

26. O’Mahony, D.; Fallon, U.B.; Hannon, F.; Kloeckner, K.; Avalos, G.; Murphy, A.W.; Kelleher, C.C. The Lifeways Cross-Generation Study: Design, recruitment and data management considerations. Ir. Med. J. 2007, 100, 3-6.

27. Kennelly, M.A.; Ainscough, K.; Lindsay, K.; Gibney, E.; Mc Carthy, M.; McAuliffe, F.M. Pregnancy, exercise and nutrition research study with smart phone app support (Pears): Study protocol of a randomized controlled trial. Contemp. Clin. Trials 2016, 46, 92-99. [CrossRef]

28. Polanska, K.; Hanke, W.; Gromadzinska, J.; Ligocka, D.; Gulczynska, E.; Sobala, W.; Wasowicz, W. Polish mother and child cohort study-Defining the problem, the aim of the study and methodological assumption. Int. J. Occup. Med. Environ. Health 2009, 22, 383-391. [CrossRef]

29. Walsh, J.M.; McGowan, C.A.; Mahony, R.; Foley, M.E.; McAuliffe, F.M. Low glycaemic index diet in pregnancy to prevent macrosomia (ROLO study): Randomised control trial. BMJ 2012, 345, e5605. [CrossRef]

30. Inskip, H.M.; Godfrey, K.M.; Robinson, S.M.; Law, C.M.; Barker, D.J.; Cooper, C. Cohort Profile: The Southampton Women's Survey. Int. J. Epidemiol. 2006, 35, 42-48. [CrossRef]

31. Deschamps, V.; de Lauzon-Guillain, B.; Lafay, L.; Borys, J.-M.; Charles, M.A.; Romon, M. Reproducibility and relative validity of a food-frequency questionnaire among French adults and adolescents. Eur. J. Clin. Nutr. 2009, 63, 282-291. [CrossRef] [PubMed]

32. Klipstein-Grobusch, K.D.; Den Breeijen, J.H.; Goldbohm, R.A.; Geleijnse, J.M.; Hofman, A.; Grobbee, D.E.; Witteman, J.C.M. Dietary assessment in the elderly: Validation of a semiquantitative food frequency questionnaire. Eur. J. Clin. Nutr. 1998, 52, 588-596. [CrossRef] [PubMed]

33. Murrin, C.; Shrivastava, A.; Kelleher, C.C. Maternal macronutrient intake during pregnancy and 5 years postpartum and associations with child weight status aged five. Eur. J. Clin. Nutr. 2013, 67, 670-679. [CrossRef] [PubMed]

34. Harrington, J. Validation of a Food Frequency Questionnaire as a Tool for Assessing Nutrient Intake. Masters' Thesis, National University of Ireland Galway, Galway, Ireland, 1997.

35. Horan, M.K.; McGowan, C.A.; Doyle, O.; McAuliffe, F.M. Well-being in pregnancy: An examination of the effect of socioeconomic, dietary and lifestyle factors including impact of a low glycaemic index dietary intervention. Eur. J. Clin. Nutr. 2014, 68, 19-24. [CrossRef] [PubMed]

36. Rogers, I.; Emmett, P. Diet during pregnancy in a population of pregnant women in South West England. ALSPAC Study Team. Avon Longitudinal Study of Pregnancy and Childhood. Eur. J. Clin. Nutr. 1998, 52, 246-250. [CrossRef] 
37. Robinson, S.; Godfrey, K.; Osmond, C.; Cox, V.; Barker, D. Evaluation of a food frequency questionnaire used to assess nutrient intakes in pregnant women. Eur. J. Clin. Nutr. 1996, 50, 302-308.

38. Miller, P.E.; Cross, A.J.; Subar, A.F.; Krebs-Smith, S.M.; Park, Y.; Powell-Wiley, T.; Hollenbeck, A.; Reedy, J. Comparison of 4 established DASH diet indexes: Examining associations of index scores and colorectal cancer. Am. J. Clin. Nutr. 2013, 98, 794-803. [CrossRef]

39. Kwan, M.W.M.; Wong, M.C.S.; Wang, H.H.X.; Liu, K.Q.L.; Lee, C.L.S.; Yan, B.P.Y.; Yu, C.M.; Griffiths, S.M. Compliance with the Dietary Approaches to Stop Hypertension (DASH) Diet: A Systematic Review. PLoS ONE 2013, 8, e78412. [CrossRef]

40. Dixon, L.B.; Subar, A.F.; Peters, U.; Weissfeld, J.L.; Bresalier, R.S.; Risch, A.; Schatzkin, A.; Hayes, R.B. Adherence to the USDA Food Guide, DASH Eating Plan, and Mediterranean dietary pattern reduces risk of colorectal adenoma. J. Nutr. 2007, 137, 2443-2450. [CrossRef]

41. U.S. Department of Health and Human Services. Your Guide to Lowering Your Blood Pressure with DASH. Report No.: NIH Publication No. 06-4082. 1998 Revised 2006; p. 64. Available online: https: //www.nhlbi.nih.gov/files/docs/public/heart/new_dash.pdf (accessed on 15 June 2018).

42. Eurocode 2. Eurocode 2 Food Coding System. Available online: http://www.ianunwin.demon.co.uk/ eurocode/index.htm (accessed on 19 February 2019).

43. Programme National Nutrition Santé. La santé vient en mangeant. Le guide alimentaire pour tous. 2002, p. 130. Available online: http://www.mangerbouger.fr/PNNS/ (accessed on 7 January 2018).

44. Programme National Nutrition Santé. La santé vient en mangeant et en bougeant. Le guide nutrition de la grossesse. 2007 Revised 2015. p. 40. Available online: http://www.mangerbouger.fr/PNNS/ (accessed on 7 January 2018).

45. Sofi, F.; Macchi, C.; Abbate, R.; Gensini, G.F.; Casini, A. Mediterranean diet and health status: An updated meta-analysis and a proposal for a literature-based adherence score. Public Health Nutr. 2014, 17, 2769-2782. [CrossRef]

46. Drouin-Chartier, J.P.; Brassard, D.; Tessier-Grenier, M.; Côté, J.A.; Labonté, M.È.; Desroches, S.; Couture, P.; Lamarche, B. Systematic Review of the Association between Dairy Product Consumption and Risk of Cardiovascular-Related Clinical Outcomes. Adv Nutr. 2016, 7, 1026-1040. [CrossRef] [PubMed]

47. Beer-Borst, S.; Hercberg, S.; Morabia, A.; Bernstein, M.S.; Galan, P.; Galasso, R.; Giampaoli, S.; McCrum, E.; Panico, S.; Preziosi, P.; et al. Dietary patterns in six european populations: Results from EURALIM, a collaborative European data harmonization and information campaign. Eur. J. Clin. Nutr. 2000, 54, 253-262. [CrossRef] [PubMed]

48. Irala-Estévez, J.D.; Groth, M.; Johansson, L.; Oltersdorf, U.; Prättälä, R.; Martínez-González, M.A. A systematic review of socio-economic differences in food habits in Europe: Consumption of fruit and vegetables. Eur. J. Clin. Nutr. 2000, 54, 706-714. [CrossRef] [PubMed]

49. Verger, P.; Ireland, J.; Møller, A.; Abravicius, J.A.; De Henauw, S.; Naska, A. Improvement of comparability of dietary intake assessment using currently available individual food consumption surveys. Eur. J. Clin. Nutr. 2002, 56 (Suppl. 2), S18-S24. [CrossRef]

50. NutriGen Alliance Investigators; De Souza, R.J.; Zulyniak, M.A.; Desai, D.; Shaikh, M.R.; Campbell, N.C.; Lefebvre, D.L.; Gupta, M.; Wilson, J.; Wahi, G.; et al. Harmonization of Food-Frequency Questionnaires and Dietary Pattern Analysis in 4 Ethnically Diverse Birth Cohorts. J. Nutr. 2016, 146, 2343-2350.

51. Mellen, P.B.; Gao, S.K.; Vitolins, M.Z.; Goff, D.C. Deteriorating dietary habits among adults with hypertension: DASH dietary accordance, NHANES 1988-1994 and 1999-2004. Arch. Intern. Med. 2008, 168, 308-314. [CrossRef]

52. Harrington, J.; Fitzgerald, A.P.; Layte, R.; Lutomski, J.; Molcho, M.; Perry, I.J. Sociodemographic, health and lifestyle predictors of poor diets. Public Health Nutr. 2011, 14, 2166-2175. [CrossRef]

53. Epstein, D.E.; Sherwood, A.; Smith, P.J.; Craighead, L.; Caccia, C.; Lin, P.H.; Babyak, M.A.; Johnson, J.J.; Hinderliter, A.; Blumenthal, J.A. Determinants and Consequences of Adherence to the DASH Diet in African American and White Adults with High Blood Pressure: Results from the ENCORE Trial. J. Acad. Nutr. Diet. 2012, 112, 1763-1773. [CrossRef]

54. Folsom, A.R.; Parker, E.D.; Harnack, L.J. Degree of concordance with DASH diet guidelines and incidence of hypertension and fatal cardiovascular disease. Am. J. Hypertens. 2007, 20, 225-232. [CrossRef] 
55. Appel, L.J.; Moore, T.J.; Obarzanek, E.; Vollmer, W.M.; Svetkey, L.P.; Sacks, F.M.; Bray, G.A.; Vogt, T.M.; Cutler, J.A.; Windhauser, M.M.; et al. A clinical trial of the effects of dietary patterns on blood pressure. DASH Collaborative Research Group. N. Engl. J. Med. 1997, 336, 1117-1124. [CrossRef]

56. Sacks, F.M.; Svetkey, L.P.; Vollmer, W.M.; Appel, L.J.; Bray, G.A.; Harsha, D.; Obarzanek, E.; Conlin, P.R.; Miller, E.R.; Simons-Morton, D.G.; et al. Effects on blood pressure of reduced dietary sodium and the Dietary Approaches to Stop Hypertension (DASH) diet. DASH-Sodium Collaborative Research Group. N. Engl. J. Med. 2001, 344, 3-10. [CrossRef]

57. Trichopoulou, A.; Naska, A.; Costacou, T.; DAFNE III Group. Disparities in food habits across Europe. Proc. Nutr. Soc. 2002, 61, 553-558. [CrossRef]

58. Micha, R.; Khatibzadeh, S.; Shi, P.; Andrews, K.G.; Engell, R.E.; Mozaffarian, D. Global, regional and national consumption of major food groups in 1990 and 2010: A systematic analysis including 266 country-specific nutrition surveys worldwide. BMJ Open 2015, 5, e008705. Available online: https: //www.ncbi.nlm.nih.gov/pmc/articles/PMC4593162/ (accessed on 19 February 2019). [CrossRef]

59. Dietary Guidelines Advisory Committee. Scientific Report of the 2015 Dietary Guidelines Advisory Committee: Advisory Report of the Secretary of Health and Human Services and the Secretary of Agriculture; U.S. Department of Agriculture, Agricultural Research Service: Washington, DC, USA, 2015.

60. Public Health England. The Eatwell Guide. 2018. Available online: https://assets.publishing.service.gov. uk/government/uploads/system/uploads/attachment_data/file/742750/Eatwell_Guide_booklet_2018v4.pdf (accessed on 22 February 2019).

61. Agudo, A.; Slimani, N.; Ocke, M.C.; Naska, A.; Miller, A.B.; Kroke, A.; Bamia, C.; Karalis, D.; Vineis, P.; Palli, D; et al. Consumption of vegetables, fruit and other plant foods in the European Prospective Investigation into Cancer and Nutrition (EPIC) cohorts from 10 European countries. Public Health Nutr. 2002, 5, 1179-1196. [CrossRef]

62. Agudo, A.; Slimani, N.; Ocke, M.C.; Naska, A.; Miller, A.B.; Kroke, A.; Bamia, C.; Karalis, D.; Vineis, P.; Palli, D.; et al. Meat, eggs, dairy products, and risk of breast cancer in the European Prospective Investigation into Cancer and Nutrition (EPIC) cohort. Am. J. Clin. Nutr. 2009, 90, 602-612.

63. Blumfield, M.L.; Hure, A.J.; MacDonald-Wicks, L.K.; Patterson, A.J.; Smith, R.; Collins, C.E. Disparities exist between National food group recommendations and the dietary intakes of women. BMC Womens Health 2011, 11, 37. [CrossRef]

64. Dehghan, M.; Martinez, S.; Zhang, X.; Seron, P.; Lanas, F.; Islam, S.; Merchant, A.T. Relative validity of an FFQ to estimate daily food and nutrient intakes for Chilean adults. Public Health Nutr. 2013, 16, 1782-1788. [CrossRef]

65. Vioque, J.; Navarrete-Muñoz, E.M.; Gimenez-Monzó, D.; García-de-la-Hera, M.; Granado, F.; Young, I.S.; Ramón, R.; Ballester, F.; Murcia, M.; Rebagliato, M.; et al. Reproducibility and validity of a food frequency questionnaire among pregnant women in a Mediterranean area. Nutr. J. 2013, 12, 26. [CrossRef]

66. Talegawkar, S.A.; Tanaka, T.; Maras, J.E.; Ferrucci, L.; Tucker, K.L. Validation of Nutrient Intake Estimates Derived Using a Semi-Quantitative FFQ against 3 Day Diet Records in the Baltimore Longitudinal Study of Aging. J. Nutr. Health Aging 2015, 19, 994-1002. [CrossRef]

(C) 2019 by the authors. Licensee MDPI, Basel, Switzerland. This article is an open access article distributed under the terms and conditions of the Creative Commons Attribution (CC BY) license (http://creativecommons.org/licenses/by/4.0/). 